\title{
Supporting Information for \\ Permeable Membranes Containing Crystalline Silicotitanate As Model Barriers For Cesium Ion
}

\section{Environmental Science and Technology}

\author{
Andrew M. Warta ${ }^{\dagger}$, William A. Arnold ${ }^{\dagger \dagger}$ and E.L. Cussler ${ }^{\dagger *}$ \\ ${ }^{\dagger}$ Department of Chemical Engineering and Materials Science \\ University of Minnesota \\ 421 Washington Ave SE \\ Minneapolis, MN 55455 \\ and \\ ${ }^{\dagger}$ Department of Civil Engineering \\ University of Minnesota \\ 500 Pillsbury Drive SE \\ Minneapolis, MN 55455
}

October 19, 2005

Materials used and membrane preparation procedures

Page S1

Figure S-1: A demonstration of the effect of depletion of upstream volumes. Page S2

Figure S-2: The effect of membrane orientation.

Page S3 
Materials. Cesium nitrate (99\%, Aldrich), sodium chloride (99.9\% Mallinckrodt), crystalline silicotitanate (CST, IONSIV-910 Lot 1998000001, UOP) and PVA (Elvanol grade 71-30 lot L1A352, molecular weight 138,000-146,500 Dupont) were used as received. DOWEX ${ }^{\circledR}$ Nonosphere ${ }^{\circledR} 550 \mathrm{~A}(\mathrm{OH})$ anion exchange resin was ground by hand with a pestle and mortar to approximately $10 \mu \mathrm{m}$ diameter particles. Distilled water was used unless otherwise specified.

Membrane Preparation. Membranes were prepared by adding $4.0 \mathrm{~g}$ of PVA to $36 \mathrm{~mL}$ of water at $90{ }^{\circ} \mathrm{C}$ and stirring at $60 \mathrm{rpm}$ in a $150 \mathrm{~mL}$ beaker on a heated stir plate for $30-60$ minutes to dissolve the PVA. The solution was removed from the stir plate and degassed under vacuum at room temperature for five minutes. For membranes containing added ion-exchangers, the degassed solution was returned to the heated stir plate, the desired amount of ion-exchanger was added and the covered solution was stirred for 2-3 more hours at $90{ }^{\circ} \mathrm{C}$. The solution was again degassed. After degassing, the covered solution was allowed to cool to room temperature. The solution was then poured onto a Teflon block, and a doctor blade was pulled by hand across the surface at about $0.5 \mathrm{~cm} / \mathrm{sec}$. The resulting film was covered with aluminum foil to minimize air convection across the surface and dried at room temperature for three days. The film was placed in an oven at $150{ }^{\circ} \mathrm{C}$ for 135 minutes to crosslink the polymer. After the film's mass was measured, it was soaked overnight in $1 \mathrm{~L}$ of water. This doubled its mass. The hydrated film was cut into circular segments of radius $2 \mathrm{~cm}$. 


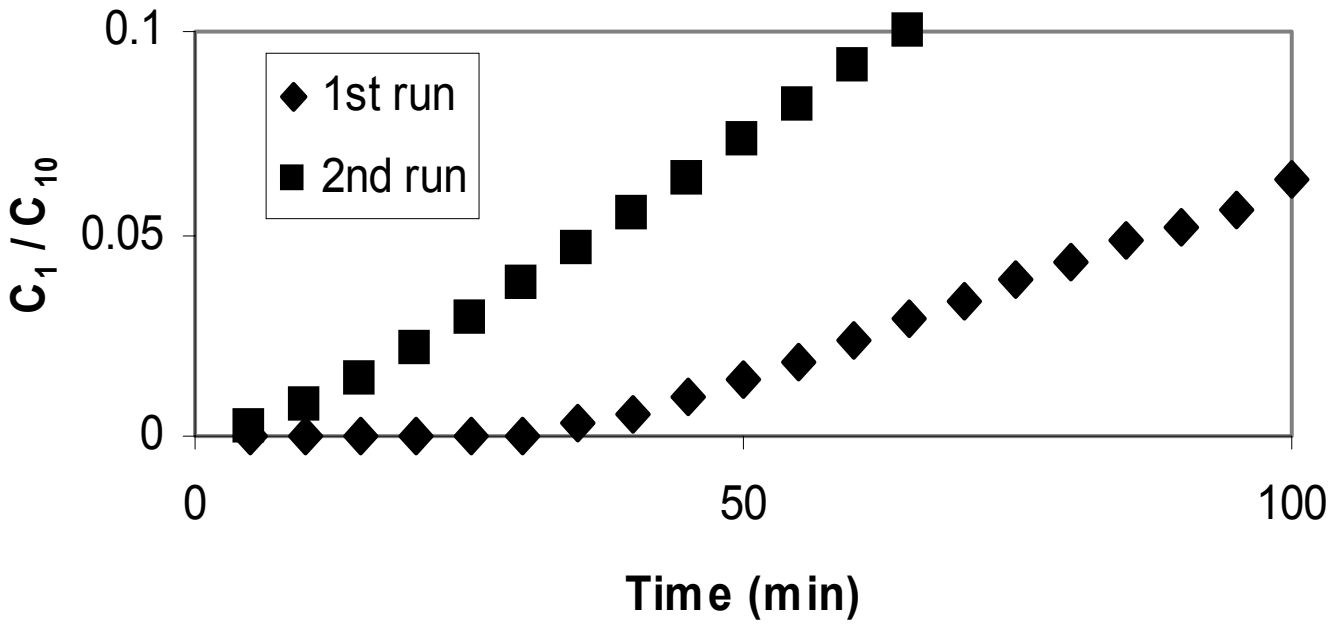

Figure S-1: A demonstration of the effect of depletion of upstream volumes. Two consecutive breakthrough experiments performed on the same $5 \mathrm{wt} \%$ CST-containing membrane with $0.001 \mathrm{M} \mathrm{CsNO}_{3}$ upstream concentration $\mathrm{C}_{10}$. The smaller slope for the first run is due to an effective decrease in $\mathrm{C}_{10}$. $\mathrm{C}_{1}$ is the $\mathrm{Cs}^{+}$concentration measured in the downstream cell. 


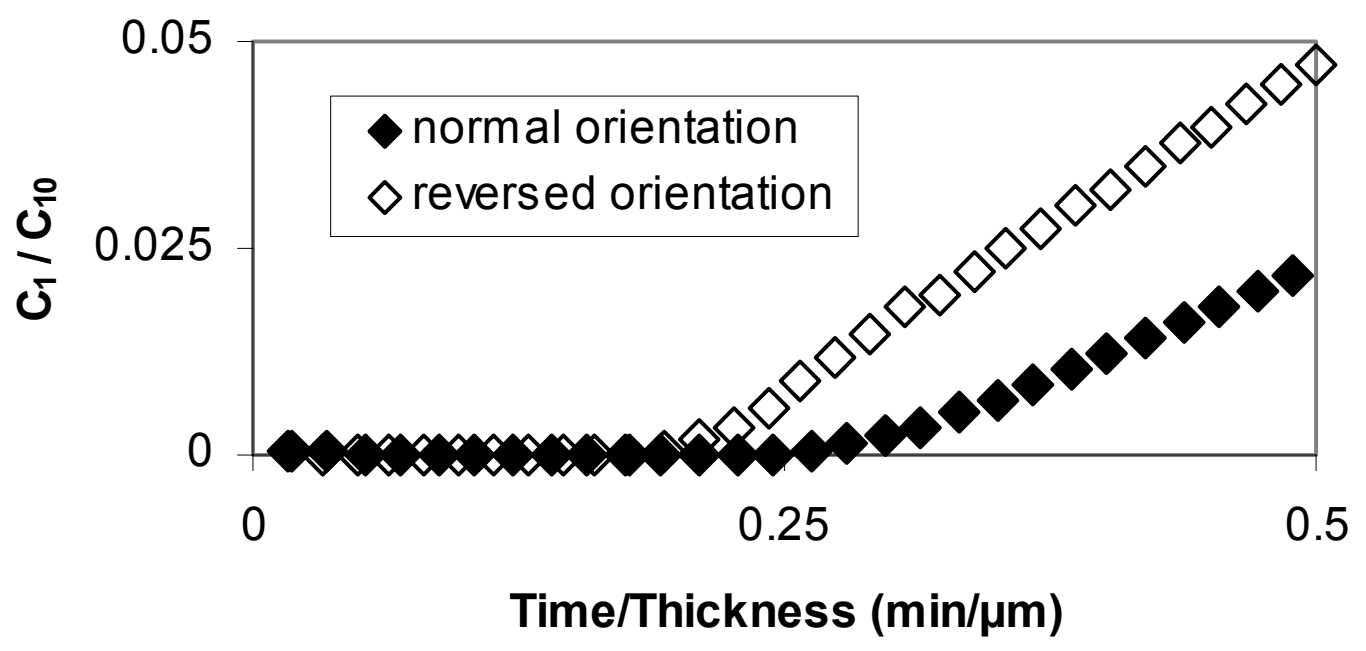

Figure S-2: This plot shows the effect of membrane orientation. Different $7.5 \mathrm{wt} \%$ CSTcontaining barrier membranes show the effect of particle settling on lag time by reversing the orientation of membrane in diffusion cell. 